Fourth International Conference on Sustainable Construction Materials and Technologies http://www.claisse.info/Proceedings.htm

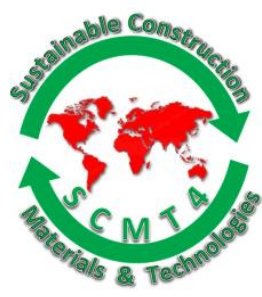

SCMT4

Las Vegas, USA, August 7-11, 2016

\title{
Evaluation of Environmental Performance and Life Cycle Costs of Construction Materials: The Case of Alternative Mastic Asphalt Mixes
}

\author{
Oliver Schwab $^{1 \mathrm{a}}$, Helmut Rechberger ${ }^{1 \mathrm{~b}}$, and Bernhard Hofko ${ }^{2}$ \\ ${ }^{1}$ Institute for Water Quality, Resource and Waste Management, Technische Universität Wien, \\ Karplsplatz.13, 1040 Vienna, Austria. ${ }^{1 a}$ Email: <oliver.schwab@tuwien.ac.at.> \\ ${ }^{2}$ Institute of Transportation, Technische Universität Wien, Gusshausstraße 28, 1040 Vienna, \\ Austria.
}

\begin{abstract}
A procedure for environmental and economic evaluation of construction materials is presented. The selection of appropriate construction materials depends on their technical suitability in particular engineered infrastructures, but also on environmental and economic considerations. The latter can be evaluated in a freely available software, combining principles of Material Flow Analysis (MFA), Life Cycle Energy Analysis (LCEA) and Life Cycle Costing (LCC). With the proposed procedure, different construction options can be compared and an optimal option can be selected.
\end{abstract}

The evaluation procedure is illustrated in a case of mastic asphalt (MA) road surface layers. The production temperature of MA can be reduced my material modifications (application of additives and varying aggregate geometries). Temperature reduction induces changes in material demand, energy demand and costs on various stages of the life cycle. A reference MA is compared to two modified, temperature-reduced mixes with similar mechanical characteristics. The results indicate that the application of a binder additive is controversial and that the complete or partial substitution of crushed aggregates by round aggregates is promising. In either case, reduction of mixing temperature results in reduction of particulate emissions and decreased energy demand. The presented evaluation procedure helps to identify cost-effective, energy-saving and low-emission MA options.

\section{INTRODUCTION}

Selection of optimal materials for engineered infrastructures is often controversial since this depends on many different variables such as mechanical properties, the engineering application, economic aspects and environmental considerations. Guidelines for assessment of mechanical properties and suitability of materials for specific infrastructure applications are widely applied and standard evaluation procedures are legally required. Also, economic tools for ensuring cost-effectiveness and environmental assessment methods for minimizing environmental impacts are sometimes applied to support informed decisions. Since different environmental aspects and costs usually depend on each other, it is beneficial to analyze 
the environmental performance and costs in parallel. As construction materials pass different stages such as production, use and demolition, a life cycle perspective on construction materials appears to be adequate. A life cycle analysis combining environmental and economic aspects is useful to selection of optimal construction material options. Such a procedure is introduced in the following and illustrated in a case study of mastic asphalt (MA).

MA is widely applied as sealing and surface layer material in special applications on bridges, in urban areas and on walk and bike ways. Because of its engineering characteristics and self-compacting behavior, MA is practical in many delicate applications. It differs from other hot mix asphalt (HMA) types in its material composition and by particularly high mixing temperatures of up to $250^{\circ} \mathrm{C}$. Due to the high temperatures, the production of MA is more energy-intensive than production of HMA. High temperatures also appear to cause higher particulate emissions in different stages of the MA life cycle, for example in production and construction. A reduction of mixing temperature may reduce energy costs and particulate emissions. In return, modifications in the MA material composition may cause higher material costs and monetary and environmental consequences may occur on various stages throughout the life cycle of MA. An optimal MA modification should minimize environmental pressure and costs while maintaining the mechanical material performance.

To understand the consequences of temperature reduction on energy demand, particulate emissions and costs, three MA mixing scenarios are compared from a life cycle perspective in a material, energy and cost dimension. Prior to the evaluation, central technical characteristics of MA are outlined and options for modifications in material composition are introduced.

The MA case study is based on investigations, data and results of Hofko et al. (2016). The emphasis of this research paper is on the procedure for combined environmental and economic evaluation of infrastructures.

\section{CHARACTERISTICS OF MASTIC ASPHALT AND MODIFICATIONS}

The viscosity of MA is lower than the viscosity of other infrastructure surface materials such as asphalt concrete. This induces the self-compacting behavior of MA, which is usually applied in $3-5 \mathrm{~cm}$ surface layers. However, reports show that the health of workers is affected increasingly by bitumen handled at high temperatures (cf. Rühl et al. (2007)). Thus, reduction of mixing temperature is of particular interest. The reduction of mixing temperature while maintaining viscosity and thus paving behavior of MA can be achieved by modification of the material composition.

MA typically consist of approximately $60 \mathrm{M} \%$ aggregates, $10 \mathrm{M} \%$ binder and $30 \mathrm{M} \%$ filler such as (CEN 2013). As filler, fine-grain material such as pulverized limestone is used. As binder, usually hard or polymer-modified bitumen $(\mathrm{PmB})$ is applied. Typical aggregates used in asphalt mixtures are crushed limestones or similar materials. In asphalt concrete, the geometry of aggregates is essential for load transfer, which happens via coarse aggregate interaction. In MA, load transfer happens via the mastic (binder plus filler). Consequently, the geometry of aggregates is not a determining factor for load transfer and crushed aggregates could be replaced by round aggregates (RA). Round aggregates would increase the flowability (i.e. reduce the viscosity) of the mix. Another option for reduction of viscosity is to add additives to the binder. These additives are usually waxes such as montane wax, polyethylene wax, Fischer-Tropsch wax or amide wax. A realistic share of waxes was observed to be up to $2-4 \%$ of the bitumen. Amid wax (AW) was found to have favorable behavior as MA additive (Hofko et al. 2015).

The three scenarios listed in Table 1 are compared in the following. Scenario 0 is a reference case of a typical MA mixture. In scenario 1, an additive is added and in scenario 2, crushed aggregates are replaced by round aggregates. Both additive and round aggregates have the ability to reduce the viscosity of the mixture and consequently to reduce the mixing temperature. 
Table 1. Material composition and mixing temperature of three scenarios

\begin{tabular}{|c|c|c|c|c|}
\hline & & $\begin{array}{c}\text { Scenario 0 } \\
\text { MA } 11\end{array}$ & $\begin{array}{l}\text { Scenario } 1 \\
\text { MA11 + } \\
\text { 4 M\% AW }\end{array}$ & $\begin{array}{c}\text { Scenario } 2 \\
\text { MA11 } \\
100 \% \text { RA + 4 M\% AW }\end{array}$ \\
\hline Binder & PmB 25/55-65 & $8.2 \mathrm{M} \%$ & $7.9 \mathrm{M} \%$ & $7.9 \mathrm{M} \%$ \\
\hline Additive & amide wax & $0 \mathrm{M} \%$ & $0.3 \mathrm{M} \%$ & $0.3 \mathrm{M} \%$ \\
\hline Filler & limestone & $27.1 \mathrm{M} \%$ & $26.3 \mathrm{M} \%$ & $27.5 \mathrm{M} \%$ \\
\hline \multirow{2}{*}{ Aggregates } & crushed & $64.7 \mathrm{M} \%$ & $65.7 \mathrm{M} \%$ & $0 \mathrm{M} \%$ \\
\hline & Round & $0 \mathrm{M} \%$ & $0 \mathrm{M} \%$ & $64.3 \mathrm{M} \%$ \\
\hline Temperature & & $240^{\circ} \mathrm{C}$ & $210^{\circ} \mathrm{C}$ & $190^{\circ} \mathrm{C}$ \\
\hline
\end{tabular}

MA11: nominal maximum aggregate size of $11 \mathrm{~mm}, \mathrm{PmB}$ : polymer modified bitumen; $A W$ : amide wax; RA: round aggregates

Compared to scenario 0 , the mixing temperature can be decreased by $30 \mathrm{~K}$ in scenario 1 and by $50 \mathrm{~K}$ in scenario 2. No adverse effects of temperature reduction on the mechanical properties of the asphalts are observed and the mechanical behavior of the construction material in the three scenarios can be assumed identical (Hofko et al. 2016). As a consequence of modified composition and temperature reduction, energy demand, emission behavior and costs for materials and process energy differ between the scenarios. These differences can be quantified with the procedure presented in the following.

\section{METHODOLOGY OF ENVIRONMENTAL AND ECONOMIC EVALUATION}

The combined environmental and economic evaluation follows the principle of life cycle thinking. Life cycle approaches attempt to evaluate products and services throughout their entire life cycle, from "cradle to grave" (Hellweg and Milà i Canals 2014). The first step of a life cycle study is the system definition. This includes the definition of life cycle stages, which usually starts with provision of raw materials, includes processing, transport and use stages and ends with demolition and potential end-of-life stages. In the MA case study, the life cycle begins at provision of raw materials and ends at demolition of MA asphalt surface. It includes the life cycle stages (1) production of MA, (2) transport of MA, (3) construction of road surface layer, (4) maintenance of road surface layer and (5) demolition of road surface layer. It also includes the "ecological backpack" of production materials, that is, the emissions and the energy demand caused for their provision. Another particularity of life cycle analyses is that they refer to a "functional unit" (FU). A FU is a defined quantity of any product or service of interest. Here, one FU is a stretch of MA road surface layer (one lane kilometer with the dimension $1000 \times 3.75 \times 0.05 \mathrm{~m}$ ). The service life of a MA surface layer is assumed to be 20 years. At the beginning of a study, the scope of the environmental evaluation has to be defined. The focuses regarding environmental pressures of MA are on particulate emissions $\left(\mathrm{PM}_{10}\right)$ and on energy demand. The life cycle, as defined in this paragraph, is the basis for the scenario analysis (three scenarios, see Table 1). 
For evaluation of the system, principles of three engineering evaluation methods are combined. First, this is Material Flow Analysis (MFA, Brunner and Rechberger (2003)), second, Life Cycle Energy Analysis (LCEA, Cabeza et al. (2014)) and third, Life Cycle Costing (LCC, Hunkeler et al. (2008)). MFA is the study of material inputs, material outputs and material flows and stocks within a defined system. LCEA considers the energy demand per FU in primary energy units, which includes process energy and embodied energy. Embodied energy does not refer to a caloric value, but to the total energy consumed for provision of a material. Consequently, the embodied energy of a material never decreases over its life cycle but typically increases. LCC is a monetary evaluation method, where costs are assigned to life cycle stages of a product or service of interest and accumulate over their life cycle. According to the principles of MFA, LCEA and LCC, material demand, energy demand and costs per FU are balanced according to the balancing framework in Figure 1.

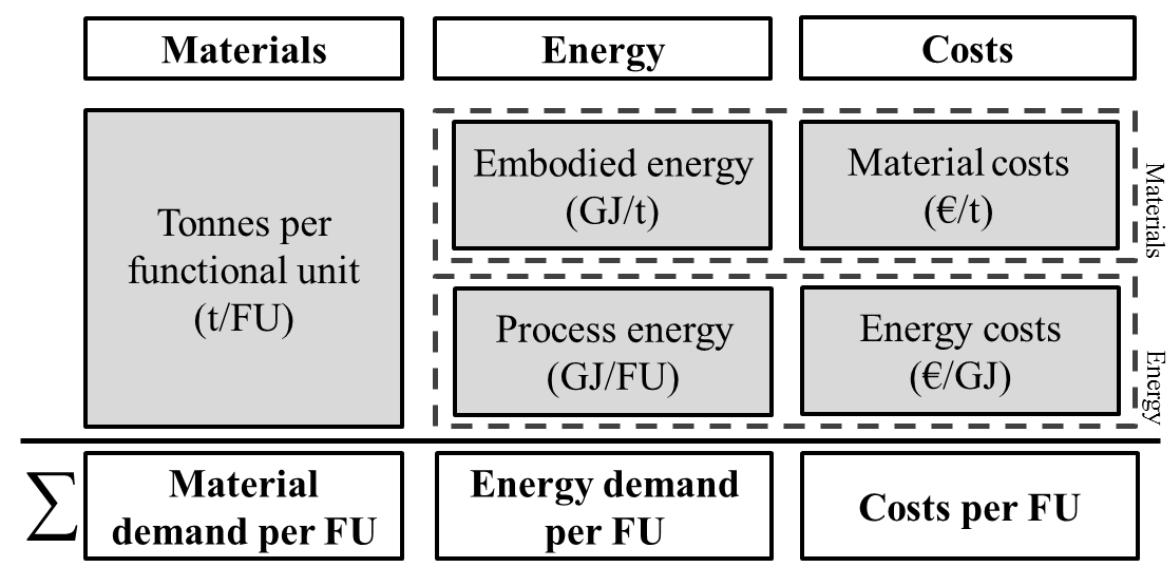

Figure 1. Balancing framework of the environmental and economic evaluation.

This is implemented in the software STAN (freely available at www.stan2web.net). STAN can be used for balancing of material systems in mass units, but it can also be applied to energy or monetary units and other quantities of interest. STAN includes the principles of mass conservation and applies algorithms for data reconciliation and error propagation (Cencic and Rechberger 2008).

STAN enables connecting evaluations of different characteristics of a quantity on so-called "layers". Here, these layers are a material layer, an energy layer and a cost layer. The layers are connected via the properties of the modelled quantity. For example, a material has a certain mass ( $t / F U)$, which contains embodied energy $(\mathrm{GJ} / \mathrm{t})$ and imposes certain material costs $(€ / \mathrm{t})$. Data necessary for the balancing the MA system are material in- and outputs ( $/ / F U)$, process energy demand (GJ/FU), embodied energy of materials $(\mathrm{GJ} / \mathrm{t})$, material costs $(€ / \mathrm{t})$ and energy costs $(€ / \mathrm{GJ})$. Data are collected from laboratory investigations, scientific literature, life cycle databases and expert interviews. For a more detailed overview of scenario input data and assumptions, refer to Hofko et al. (2016). Embodied energy does obviously not cause energy costs, but increases throughout the life cycle as a consequence of included process energy which in return imposes additional energy costs. Embodied energy and costs are not assigned to residuals and emissions. Embodied energy and costs are allocated only to the desired outputs of the processes (MA mix, road surface) and to the final material output "solid residuals" of the demolition phase. The results are displayed as tables or as Sankey diagrams. Sankey diagrams illustrate flows of a modelled quantity (here: materials, energy, costs) between processes (here: between life cycle stages) by the width of the flow arrows. Sankey diagrams are a typical output of the applied software STAN. In the following, results regarding the environmental performance ( $\mathrm{PM}_{10}$ emissions and energy demand) are presented. 


\section{ENVIRONMENTAL PERFORMANCE}

Approximately 460 tonnes of materials are needed for construction of one lane kilometer MA surface layer and additional 10 tonnes for maintenance and losses. Ninety M\% are mineral materials (aggregates, filler) and $10 \mathrm{M} \%$ are organic materials (binder, additive). One FU includes about 300 tonnes of aggregates, 130 tonnes of filler, 35 tonnes of bitumen and 1.5 tonnes of additive. A balance of $\mathrm{PM}_{10}$ emissions during material provision ("ecological backpack"), asphalt production, transport, construction, maintenance and demolition is presented in Table 2.

\section{Table 2. Balance of $\mathrm{PM}_{10}$ emissions during various life cycle stages per functional unit of MA road surface layer}

\begin{tabular}{|c|c|c|c|c|c|c|c|c|c|}
\hline \multirow[b]{2}{*}{$\begin{array}{l}\text { Particulates } \\
(\mathrm{kg} / \mathrm{kg})\end{array}$} & \multicolumn{3}{|c|}{ Scenario 0 (reference mix) } & \multicolumn{3}{|c|}{ Scenario 1} & \multicolumn{3}{|l|}{ Scenario 3} \\
\hline & $\begin{array}{l}\text { Material } \\
\text { quantity } \\
\text { (t/FU) }\end{array}$ & $\begin{array}{l}\text { Partic. } \\
\text { (kg/FU) }\end{array}$ & $\begin{array}{l}\text { share } \\
(\%)\end{array}$ & $\begin{array}{c}\text { Material } \\
\text { quantity } \\
\text { t/FU }\end{array}$ & $\begin{array}{c}\text { Partic. } \\
\text { (kg/FU) }\end{array}$ & $\begin{array}{c}\Delta \text { to } \\
\text { scen. } 0 \\
(\%)\end{array}$ & $\begin{array}{c}\text { Material } \\
\text { quantity } \\
\text { t/FU }\end{array}$ & $\begin{array}{c}\text { Partic. } \\
\text { (kg/FU) }\end{array}$ & $\begin{array}{c}\Delta \text { to } \\
\text { scen. } 0 \\
(\%)\end{array}$ \\
\hline
\end{tabular}

Ecological backpack (particulate emissions) of raw materials

\begin{tabular}{|c|c|c|c|c|c|c|c|c|c|c|}
\hline Aggregate (crushed) & $1.98 \mathrm{E}-06$ & 306 & 0.6 & 1.4 & 310 & 0.6 & 1.3 & 0 & 0.0 & NA \\
\hline Aggregate (round) & $1.62 \mathrm{E}-06$ & 0 & 0.0 & 0.0 & 0 & 0.0 & 0.0 & 304 & 0.5 & NA \\
\hline Filler & $2.42 \mathrm{E}-06$ & 128 & 0.3 & 0.7 & 124 & 0.3 & -3.1 & 130 & 0.3 & 1.7 \\
\hline Bitumen & $2.65 \mathrm{E}-04$ & 39 & 10.3 & 24.3 & 37 & 9.9 & -4.0 & 37 & 9.9 & -4.0 \\
\hline Additive & $2.56 \mathrm{E}-06$ & 0 & 0.0 & 0.0 & 2 & 0.0 & NA & 2 & 0.0 & NA \\
\hline \multicolumn{11}{|l|}{ Process emissions } \\
\hline \multicolumn{3}{|l|}{ Production (energy) } & 7.4 & 17.6 & & 6.8 & -9.0 & & 6.0 & -18.7 \\
\hline \multicolumn{3}{|c|}{ Transport (transportation energy) } & 0.5 & 1.2 & & 0.5 & 0.0 & & 0.5 & 0 \\
\hline \multicolumn{3}{|c|}{$\begin{array}{l}\text { Construction (energy for machinery, placing of } \\
\text { asphalt) }\end{array}$} & 19.9 & 47.0 & & 12.0 & -39.6 & & 4.1 & -79.2 \\
\hline \multicolumn{3}{|c|}{$\begin{array}{l}\text { Maintenance (energy for machinery, demolition } \\
\text { dust, constr. activity) }\end{array}$} & 1.3 & 3.0 & & 1.3 & 0.0 & & 1.3 & 0 \\
\hline \multicolumn{3}{|c|}{$\begin{array}{l}\text { Demolition (energy for machinery, demolition } \\
\text { dust) }\end{array}$} & 2.0 & 4.7 & & 2.0 & 0.0 & & 2.0 & 0 \\
\hline \multicolumn{3}{|l|}{ TOTAL } & 42.3 & 100 & & 33.3 & -21.3 & & 24.6 & -41.8 \\
\hline
\end{tabular}

Emission data: Ecoinvent v3.1 for aggregate (crushed), aggregate (round), filler. Emission of nylon production from ecoinvent v3.1 for additives. Eurobitumen 2012 for Bitumen. Construction emissions according to estimations by Hofko et al. (2016). Process emissions from scenario calculations based on ecoinvent v3.1 data. Material demand according to Table 1 scaled to one FU.

According to Table 2, one FU causes about $40 \mathrm{~kg}$ pf $\mathrm{PM}_{10}$ emissions (Scenario 0) which can be reduced by $20 \%$ (Scenario 1) or $40 \%$ (Scenario 2). Emissions originate either from the material itself (for example from the hot bitumen) or from combustion of fuels for provision of process energy. A substantial share of the $\mathrm{PM}_{10}$ is emitted during the construction phase as aerosols from the hot mix. Other potentially significant sources of emissions such as road wear (road surface abrasion) are not considered since there is little information on particulate matter released from road surfaces via abrasion (Thorpe and Harrison 2008). Despite the probably high quantities of $\mathrm{PM}_{10}$ from road wear compared to other life cycle stages, it can be questioned if changes in material composition as listed in Table 1 have qualitative or quantitative consequence on the abraded matter. Certainly, particulate loads impose different environmental impacts depending on the location and the duration of their emissions. Aerosols from construction mainly affect workers in spatial proximity to the hot mix, while particulates from road wear primarily impact on soil and aquatic environments via surface runoff (Unice et al. 2013). 
Compared to other types of asphalt, MA is found to be particularly energy intensive because of the high mixing temperatures. Throughout the life cycle of one FU, 500-600 GJ are consumed and consequently "embodied" in the solid demolition residuals (see Figure 2). Temperature reduction in scenarios 1 and 2 implies process energy savings in production. Since amide wax is comparatively energy-intensive in its production, the total embodied energy per FU is higher in Scenario 1. The application of little energyintensive round aggregates in Scenario 2 reduces the total embodied energy from 556 GJ in Scenario 0 to 511 GJ. Although the production phase causes about $90 \%$ of the process energy demand, embodied energy of materials appears to be the determining factor for the total embodied energy (see output flow "solid residuals" from demolition). Savings in production energy do hence not necessarily lead to decreasing total embodied energy.

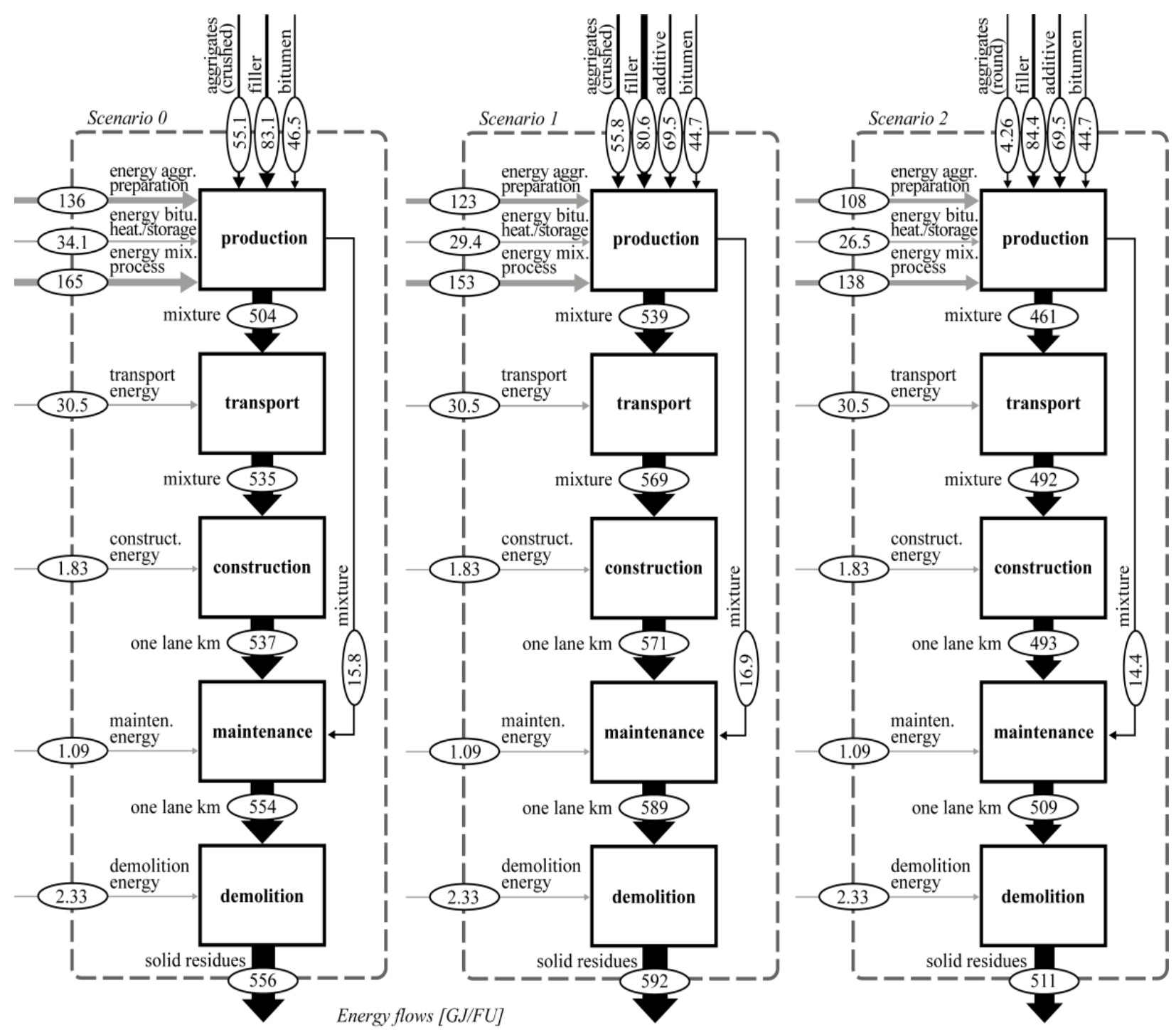

Figure 2. Three scenarios of the energy consumption per lane kilometer MA road surface layer with a service life of 20 years. Black arrows indicate embodied energy, grey arrows (from the left) indicate process energy. 


\section{LIFE CYCLE COSTS}

The costs per FU sum up to $30,000 €-35,000 €$ (Figure 3). Up to $95 \%$ of the total costs are material costs. A major share of the process energy costs allocate to the life cycle stage "production". The cost savings by temperature reduction seem to be low when considering one FU but, due to the economics of scale, may be relevant for asphalt producers. The costs of additives do, however, outweigh the economic benefit of temperature reduction.

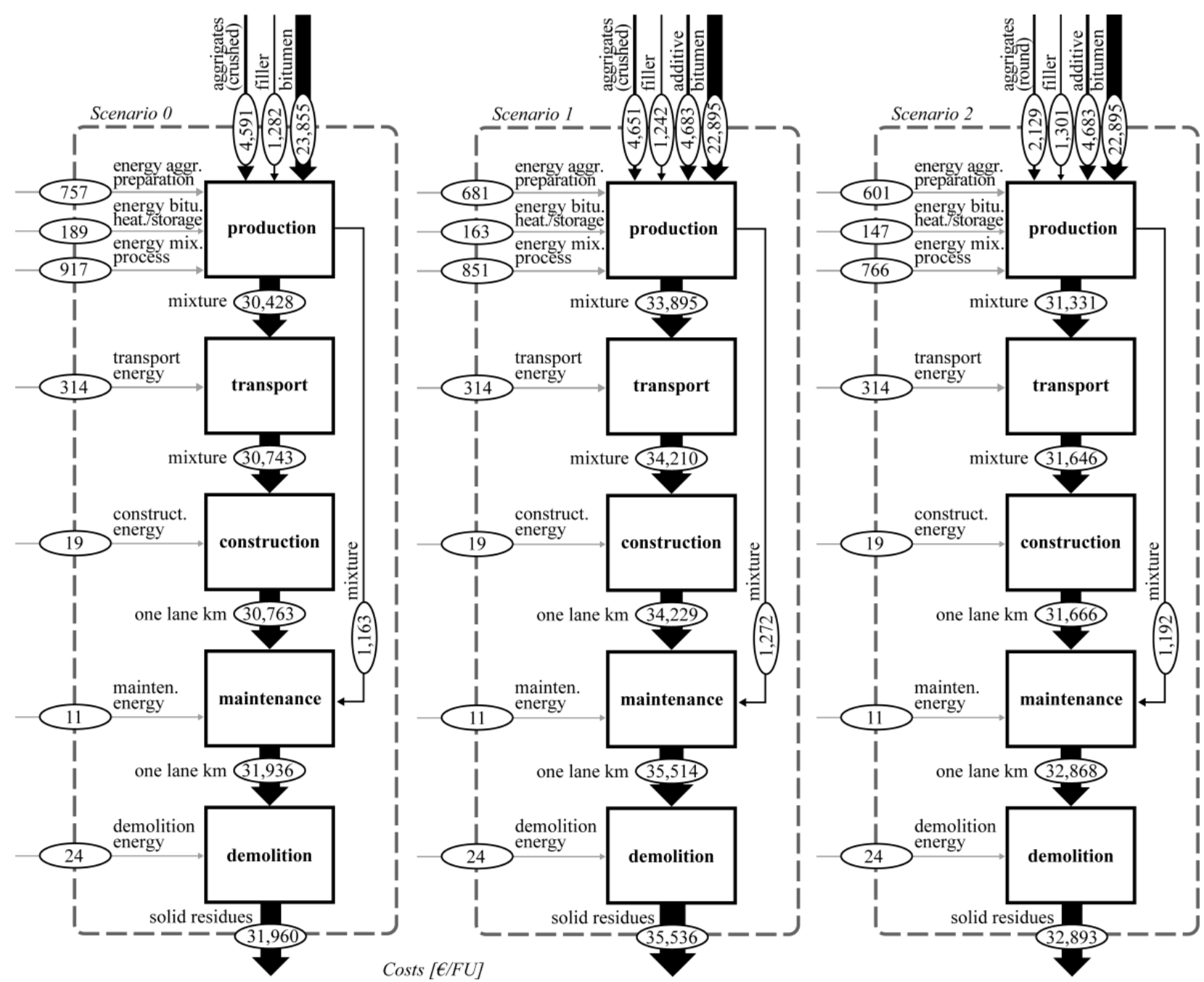

Figure 3. Three scenarios of the costs per lane kilometer MA road surface layer with a service life of 20 years. Material costs (inputs from above) and energy costs (inputs from the left) and total costs (output "solid residuals").

Although scenario 1 is beneficial compared to scenario 0 regarding $\mathrm{PM}_{10}$ emissions (Table 2), it is unfavorable regarding energy demand (Figure 2) and life cycle costs (Figure 3). That is, because process energy savings by temperature reduction are outnumbered by additional embodied energy and comparatively high material costs of the additive. The substitution of crushed aggregates by comparatively little energy-intensive and more cost-efficient rounded aggregates in scenario 2 leads to positive changes in the balances of particulates and energy demand, but causes higher costs compared to scenario 0 . By adjusted combination of round aggregates and additives (i.e. a mix between scenario 1 and 2), an energy-efficient, low-emission and cost-neutral option could be designed. 


\section{DISCUSSION AND CONCLUSIONS}

A balancing framework for combined environmental and economic evaluation of construction materials from a life cycle perspective has been presented and illustrated in a case study of modified mastic asphalt (MA) road pavements. In combination with evaluations of the mechanical properties of modified materials, the results can contribute to informed decision making and hence to selection of an optimal option. Since there are no considerable differences between the mechanical properties of the modified MA mixes (scenario 1 and 2) and the reference mix (scenario 0) (Hofko et al. 2016), the results of the evaluation procedure indicate that a more energy-efficient option with reduced $\mathrm{PM}_{10}$ emissions at equal costs could be a MA mix between scenario 1 and scenario 2 (round aggregates and amide wax with a share below $4 \mathrm{M} \%$ of the binder).

Two of the most critical points of the balancing approach are the (1) system definition and the (2) reliability of input data. (1) refers to the fact that model results certainly depend on the system definition and choices. In the here presented case study, particulate emissions from the production process were assumed to arise only from the combustion of energy carriers. It may be argued that asphalt mixing plants have, despite efficient filters of off-gases, still considerable diffuse particulate emissions which should also be considered in the balancing framework. Also, particulate emissions from other processes such as road wear may be relevant. Regarding (2) it can be said that the here presented balances are based on best available information. Some flows were quantified based on assumptions and expert estimations, for example regarding material losses and demand of maintenance materials. Generally speaking, model input data is most reliable regarding material inputs and embodied energy of materials, less reliable for process energy and costs and the least reliable for material outputs and emissions.

End of life stages of construction materials are usually controversial in life cycle analysis. In this study it was chosen that the downstream end of the system is a quantity of solid residual material (tonnes/FU) arising at the site from milling of the MA pavement. The milling process is considered as part of the analysis, but not the further management of the residual material. To the current state of technology, MA is always produced from virgin materials and not from recycled pavement. However, milled MA pavement has not necessarily to be landfilled but may, according to relevant legal constrains, either be downcycled in road base layers or added to production of certain types of hot mix asphalt where it can replace primary materials up to a certain share (about $20 \%$ to the current state of technology). Whichever end-of-life option is chosen for milled MA pavement, it can be assumed that a change in material composition (see Table 1) does not change the suitability of the material for end-of-life uses. Thus, potential changes in end of life options are not due to material characteristics but because of other considerations such as legislative or economic constrains.

Certainly, other critical emissions are caused at various stages of the MA pavement life cycle. Regarding the evaluation procedure of materials, all outputs of the studied processes should be included for creation of closed material balances. In the case study, this could be for example $\mathrm{CO}_{2}$ emissions ("CO footprint"), among others. A reason for not integrating all emissions might be that the main interest of a study is on particular environmental loads, such as $\mathrm{PM}_{10}$ in the here presented case study. However, the order of magnitude of some input flows (here: several hundred tonnes per FU) is considerably higher than that of some output flows (here: grams per FU). Some of these low-quantity flows apparently might perish in the uncertainties of other, high quantity flows, what might hinder the development of full material balances in this case. For presentation of results on low-quantity flows, tables (such as Table 2 for $\mathrm{PM}_{10}$ emissions) might be more useful than Sankey diagrams.

A question regarding the evaluation of energy is the allocation of process energy to materials as embodied energy. Energy can be allocated to all materials according to flow quantities ("physical allocation"). In the case study, this would mean that energy allocates both to the asphalt mix and to emissions and losses. 
Since emissions are regarded as unwanted by-products, all energy is here allocated to the desired products of the process, that is, the MA mix or MA road surface layer ("economic allocation"). The same consideration applies for the cost evaluation.

The evaluation of life cycle costs can also be extended by other costs such as labor costs and infrastructure costs. In this study, the focus is on material and energy costs since these are directly related to material composition and mixing process. Modifications of material composition and mixing temperature do, in the case presented here, not have direct consequences for labor and infrastructure costs.

The proposed framework contributes to integrated consideration of multiple decision-relevant dimensions for selection of construction materials. Two possible options for further research are (1) the application of the framework to other case studies (for example other road surface materials such as other asphalt types or concrete roads) and (2) the broadening and deepening of the MA case study based on field work and investigations at asphalt mixing plants.

\section{ACKNOWLEDGEMENTS}

This research was funded by the Austrian Research Promotion Agency (FFG). The authors thank the colleagues at the Institute for Transportation, TU Wien (Mariyan Dimitrov) and at the Institute for Material Chemistry, TU Wien (Hinrich Grothe and Fabian Weiss) for their contribution to the case study. The authors thank Andrea Di Maria (KU Leuven, Belgium) for useful comments on a previous version of this paper.

\section{REFERENCES}

Brunner, P. H. and H. Rechberger. 2003. Practical Handbook of Material Flow Analysis: CRC Press.

Cabeza, L. F., L. Rincón, V. Vilariño, G. Pérez, and A. Castell. 2014. Life cycle assessment (LCA) and life cycle energy analysis (LCEA) of buildings and the building sector: A review. Renewable and Sustainable Energy Reviews 29: 394-416.

CEN. 2013. Bitumous mixtures - Material specifications - Part 6: Mastic Asphalt. Brussels: European Committee for Standardization.

Cencic, O. and H. Rechberger. 2008. Material Flow Analysis with Software STAN. Journal of Environmental Engineering Management 18(1): 3-7.

Hellweg, S. and L. Milà i Canals. 2014. Emerging approaches, challenges and opportunities in life cycle assessment. Science 344(6188): 1109-1113.

Hofko, B., M. Dimitrov, and M. Hospodka. 2015. Assessing temperature reduction potential of various additives on binder and asphalt mix level for mastic asphalt. In 6th International Conference on Bitumous Mixtures and Pavements, edited by A. F. Nikolaides. Thessaloniki, Greece: CRC Press.

Hofko, B., M. Dimitriv, O. Schwab, F. Weiss, H. Rechberger, and H. Grothe. 2016. Technological and environmental performance of temperature-reduced mastic asphalt mixtures. Road Materials and pavement design: 1-16.

Hunkeler, D., K. Lichtenvort, G. Rebitzer, A. Ciroth, and SETAC-Europe. 2008. Environmental Life Cycle Costing: Taylor \& Francis. 
Rühl, R., U. Musanke, K. Kolmsee, R. Prieß, and D. Breuer. 2007. Bitumen Emissions on Workplaces in Germany. Journal of Occupational and Environmental Hygiene 4(sup1): $77-$ 86.

Thorpe, A. and R. M. Harrison. 2008. Sources and properties of non-exhaust particulate matter from road traffic: A review. Science of The Total Environment 400(1-3): 270-282.

Unice, K. M., M. L. Kreider, and J. M. Panko. 2013. Comparison of Tire and Road Wear Particle Concentrations in Sediment for Watersheds in France, Japan, and the United States by Quantitative Pyrolysis GC/MS Analysis. Environmental Science \& Technology 47(15): 81388147. 